ORIGINAL ARTICLE

AFRICAN JOURNAL OF CLINICAL AND EXPERIMENTAL MICROBIOLOGY

AJCEM/21305

COPYRIGHT 2013 http://dx.doi.org/10.4314/ajcem.v14i1.6

AFR. J. CLN. EXPER. MICROBIOL 14(1): 23-28
JANUARY2013 ISBN 1595-689X VOL 14(1) 2013

-http://www.ajol.info/journals/ajcem

\title{
PREVALENCE AND SUSCEPTIBILITY PATTERNS OF CLINICAL ISOLATES OF ESCHERICHIA COLI TO VARIOUS ANTIMICROBIALS IN A CLINICAL MICROBIOLOGY LABORATORY IN SOUTH-SOUTH NIGERIA
}

\author{
Oreha $^{a},{ }^{*}$ N. C., Esimone ${ }^{b}$, C. O. \& Ekwunife ${ }^{c}$ O. I.a. \\ a.Department of Pharmaceutical Microbiology, Faculty of Pharmaceutical Sciences, University of Port Harcourt, \\ Rivers State; b. Department of Pharmaceutical Microbiology and Biotechnology, Faculty of Pharmaceutical \\ Sciences, Nnamdi Azikiwe University, Awka, Anambra State; c.Department of Clinical Pharmacy and Pharmacy \\ Management, Faculty of Pharmaceutical Sciences, University of Nigeria, Nsukka, Enugu State.
}

Correspondence: Oreh, N. C. E mail: chineizukanne@yahoo.co.uk

\section{RUNNING TITLE: ANTIMICROBIAL SUSCEPTIBILITY OF ESCHERICHIA COLI}

\begin{abstract}
The purpose of this study is to determine the prevalence of Escherichia coli as an aetiologic agent in bacterial infections and its antimicrobial susceptibility patterns to ciprofloxacin, ofloxacin, norfloxacin, perfloxacin, gentamycin and cotrimoxazole as a guide for empiric therapy. A retrospective study was carried out using a clinical microbiology laboratory in Nigeria. Data retrieved include number of E. coli isolates, sources of the isolates and their antimicrobial susceptibility to various fluoroquinolones, gentamycin and cotrimoxazole between 2005 and 2009. Statistical analysis was carried out using SPSS version 14, Chicago IL. Out of a total of 906 bacterial isolates, E. coli accounted for $23 \%$ (211) of the isolates. Thirty-eight percent (38.39\%) was isolated from urine samples, $27.96 \%$ from high vaginal swab samples, $24.17 \%$ from stool samples, $0.95 \%$ from urethra swabs, $1.9 \%$ from wound swabs and $6.6 \%$ from semen samples. There was poor level of susceptibility to norfloxacin $(2.2 \%)$ and cotrimoxazole $(23.7 \%)$, susceptibility to ofloxacin, ciprofloxacin and pefloxacin were $51.1 \%, 54.7 \%$ and $52.5 \%$ respectively, that of gentamycin was $51.8 \%$. The trends across the years showed a significant increase in susceptibility to ciprofloxacin, pefloxacin and ofloxacin in 2007 after which it started reducing, while norfloxacin's susceptibility was low across the five years with maximum susceptibility at $9.1 \%$ in 2006. There was an increase in susceptibility to gentamycin as the susceptibility levels of the fluoroquinolones were reducing. There should be continuous surveillance of antimicrobial susceptibility patterns and empiric treatment with fluoroquinolones discouraged, especially for non urinary tract infections.
\end{abstract}

KEYWORDS: Antimicrobial susceptibility, Nigeria, Escherichia coli, fluoroquinolones, gentamycin

\section{INTRODUCTION}

Antimicrobial resistance is a worldwide problem and it is one of the greatest challenges to health care delivery[1]. There is tremendous variability in antimicrobial resistance patterns not only among pathogens causing various clinical infections but also in different geographical regions and over time [2]. Surveillance of susceptibility patterns of pathogens to antimicrobial agents is therefore, important in the monitoring and detection of increase in resistance [3-5]. It is very helpful for clinicians in prescribing antimicrobial agents especially in cases where empiric treatment is employed. In Nigeria, as is the case in many developing countries, empiric therapy is often employed as a result of inadequate staffing and laboratory facilities [6].

E.coli has been identified as a predominant pathogen for various bacterial infections especially urinary tract infections [7-11]. Fluoroquinolones have been proven to be highly effective broad spectrum agents especially against those infections caused by Gram-negative organisms.[12] Due to high resistance to cotrimoxazole, fluoroquinolones became the first drug of choice for empiric treatment of urinary tract infections and other infections caused by Gram-negative bacteria and its widespread use has resulted in the rise in their resistance.[13] Despite the regular use of empiric treatment in Nigeria, data on antimicrobial susceptibility patterns of various pathogens are scant. This study was therefore carried out to determine prevalence of $E$. coli as an aetiologic agent in community acquired bacterial infections and its antimicrobial susceptibility patterns to different fluoroquinolones, as well as gentamycin and cotrimoxazole, as a guide for empiric therapy. 


\section{METHODS}

This was a single centre retrospective study done between January 2005 and December 2009 in a clinical microbiology laboratory in South-south Nigeria. Data retrieved from microbiology laboratory records included number of $E$. coli isolates, sources of the isolates and antimicrobial susceptibility to ciprofloxacin, ofloxacin, pefloxacin, and norfloxacin (fluoroquinolones) and also cotrimoxazole and gentamycin, popularly used in the country for the treatment of bacterial infections. Isolates collected from the same specimen source within seven days were excluded. Samples were inoculated on blood agar, MacConkey agar and urine samples on cystine lactose electrolyte deficient (CLED) agar. Culture plates were incubated at $37 \mathrm{oC}$ for 24 hours. Identification was done using Gram staining and confirmatory tests were carried out. Antimicrobial susceptibility test was carried out using antibiotic discs on Mueller Hinton agar. Antibiotic discs used were gentamycin $(10 \mathrm{mcg})$, cotrimoxazole $25 \mathrm{mcg}$, ciprofloxacin (10mcg), ofloxacin (10mcg), norfloxacin (10mcg) and pefloxacin $(10 \mathrm{mcg})$. Results were interpreted according to Clinical and Laboratory Standards Institute (CLSI) guidelines [14],. Susceptibility tests were classified into two categories - susceptible and

TABLE 1: PREVALENCE OF ESCHERICHIA COLI

FROM THE VARIOUS SOURCES

\begin{tabular}{|c|c|c|}
\hline Source & $\begin{array}{l}\text { Prevalence } \\
(\%)\end{array}$ & $\begin{array}{c}\text { No of E.coli isolates/total no } \\
\text { of samples tested }\end{array}$ \\
\hline Urine & 33.37 & $81 / 243$ \\
\hline Stool & 26.56 & $51 / 192$ \\
\hline HVS & 15.86 & $59 / 372$ \\
\hline $\begin{array}{l}\text { Urethra } \\
\text { swab }\end{array}$ & 9.1 & \\
\hline Wound & 15.35 & $4 / 26$ \\
\hline Semen & 25.93 & $14 / 54$ \\
\hline
\end{tabular}

resistant, with all intermediate susceptibility classified as resistant. For quality control of susceptibility tests, E.coli ATCC 27922 was used.

Analysis of data was carried out using SPSS version 14, Chicago IL. Frequency of E.coli and susceptibility results were expressed as percentages.

\section{RESULTS}

There was a total of 906 bacterial isolates within the time frame (2005-2009) included in this study. Of this 906 , E. coli accounted for $23 \%$ (211). Frequency of the $211 \mathrm{E}$. coli isolates from various sources is shown in Fig. 1. Table 2 shows the prevalence of $E$. coli in the various sources. The total percentage susceptibility of levels of E.coli to the various fluoroquinolones is shown in Table 2.

The susceptibility trends of E.coli to pefloxacin, ciprofloxacin and ofloxacin were similar across the five years (Fig 2). The level of norfloxacin susceptibility across the five years was below $10 \%$ with the highest susceptibility level in 2006 at 9.1\%. Susceptibility to gentamycin was lowest $(27.3 \%)$ in 2006 and it kept increasing till it got to its highest $(81.8 \%)$ in 2009.

TABLE 2: ANTIBIOTIC SUSCEPTIBILITIES OF ALL $E$. COLI

ISOLATES TO ANTIMICROBIALS UNDER STUDY

BETWEEN 2005 AND 2009

\begin{tabular}{|l|l|}
\hline ANTIMICROBIAL & $\%$ SUSCEPTIBILITY \\
\hline OFLOXACIN & $108 / 211(51.1)$ \\
\hline CIPROFLOXACIN & $115 / 211(54.7)$ \\
\hline NORFLOXACIN & $4 / 211(2.2)$ \\
\hline PEFLOXACIN & $111 / 211(52.5)$ \\
\hline COTRIMOXAZOLE & $50 / 211(23.7)$ \\
\hline GENTAMYCIN & $109 / 211(51.8)$ \\
\hline
\end{tabular}




\section{DISCUSSION}

The results show that $E$. coli is an important pathogen in community acquired bacterial infections especially in urinary tract infections, which accounts for $38.39 \%$ of all the E. coli isolates. Its prevalence in urine samples was also high $33.37 \%$. Prevalence of E.coli in stool samples was $26.56 \%$ and prevalence in high vaginal swab samples (HVS) was $15.86 \%$. This could be as because of the proximity of the vagina to the anus.

The results also show similar susceptibility levels among the three second generation fluoroquinolones, ciprofloxacin (54.7\%), pefloxacin (52.5\%) and ofloxacin $(51.1 \%)$, included in the study. Susceptibility of ciprofloxacin is similar to that found in a study carried out in Tehran [15].

FIG 1: FREQUENCY OF ESCHERICHIA COLI FROM VARIOUS SOURCES.

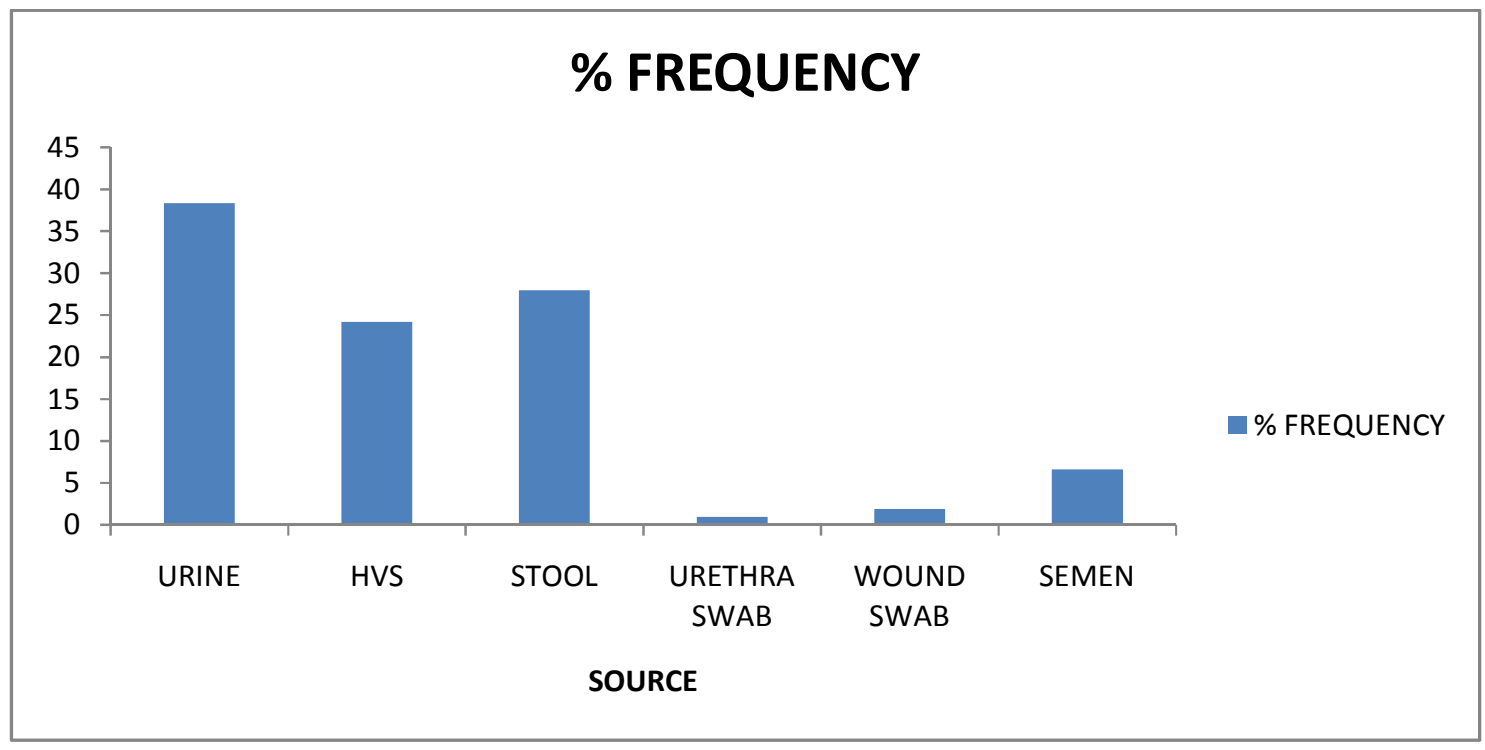

Fig 2: SUSCEPTIBILITY TRENDS OF E. COLI TO VARIOUS ANTIMICROBIALS BETWEEN 2005 AND 2009

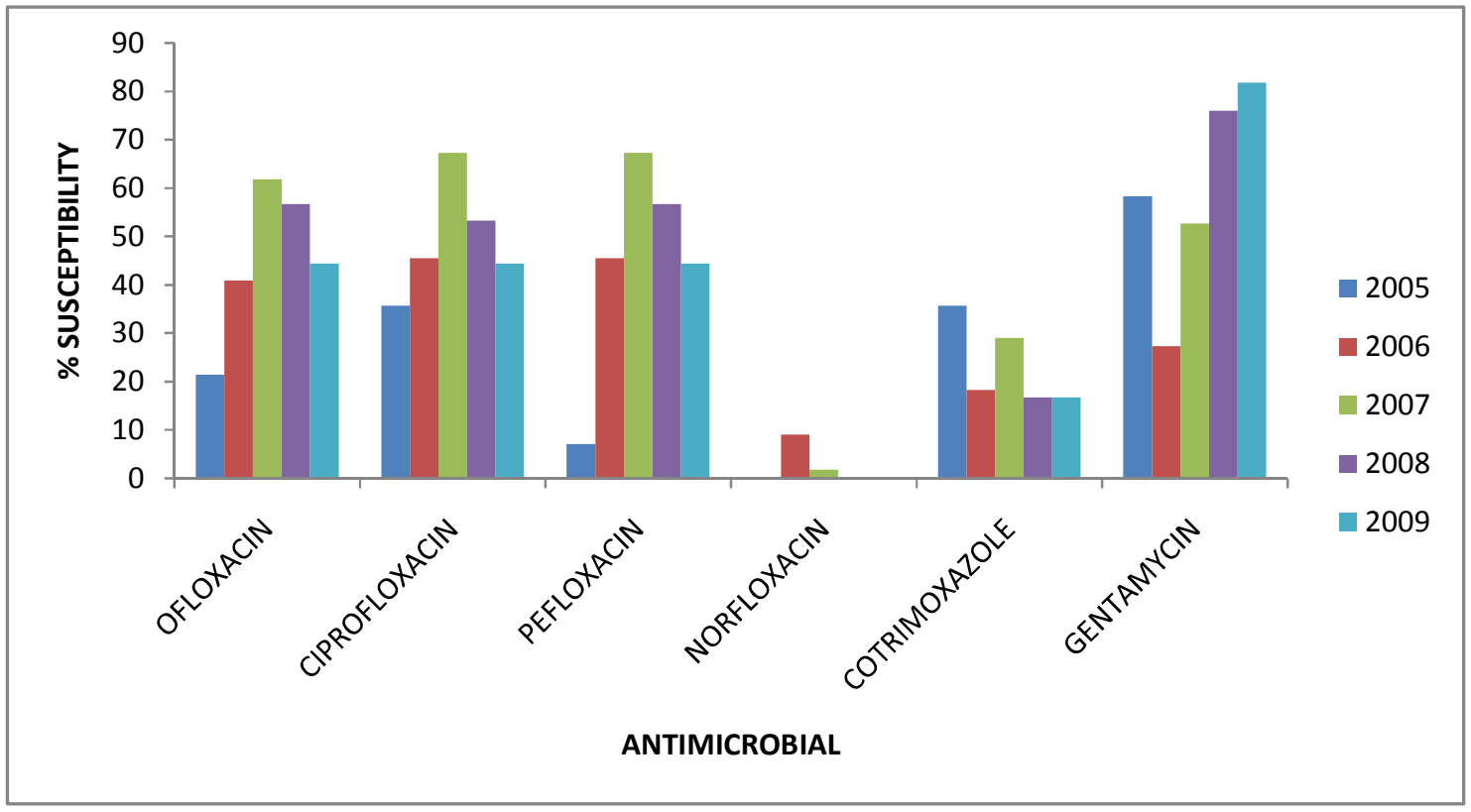


Ciprofloxacin susceptibility was the highest. This is also in line with a study carried out in France [16] . Susceptibility to gentamycin $(51.8 \%)$ was also similar to that of the fluoroquinolones. However, there was poor susceptibility to cotrimoxazole and norfloxacin. Susceptibility levels for cotrimoxazole in this study was $23.7 \%$. This is similar to other studies carried out in other places [11,17]. Poor susceptibility of E.coli to cotrimoxazole could possibly be as a result of the fact that it has been in use for a long time, hence giving organisms time to develop resistance mechanisms towards it

counter in Nigeria, which is also the case in many other resource poor settings with lax policies, resulting in high and uncontrolled consumption of antibiotics. There has been a steady increase in the level of resistance of commonly used antibiotics. Ciprofloxacin, ofloxacin and pefloxacin were almost at par with susceptibility of just over $50 \%$.. In the rural Tamilinadu study, antimicrobial susceptibility of E.coli from urine isolates to ciprofloxacin was $77.7 \%[18]$

The susceptibility trends across the five years show an increase in susceptibility levels of ciprofloxacin, ofloxacin and pefloxaciin. In 2007, susceptibility of ciprofloxacin increased from $35.7 \%$ in 2005 to $67.3 \%$ in 2007; that of ofloxacin increased from $21.4 \%$ in 2005 to $61.8 \%$ in 2007 while that of pefloxacin increased from $7.1 \%$ in 2005 to $67.3 \%$ after which the susceptibility levels started dipping again. This could possibly be due to a reduction in its use prior to 2007 and the subsequent increase in resistance after 2007 might have arisen as a result of increased use. However, this cannot clearly be ascertained from this study. It was also observed that the susceptibility levels of gentamycin, an aminoglycoside, increased (27.3\% in 2006 and $81.8 \%$ in 2009) as susceptibility levels of the fluoroquinolones were reducing. It should be recommended that antibiotic use be rotated. Antibiotic cycling which is the rotation of antibiotics over a stipulated time period is an important aspect in antibiotic stewardship. A study in Greece [1] showed significant increase in the susceptibility of three important Gram negative pathogens to ciprofloxacin following an eighteen month restriction on the empirical use of fluoroquinolones in the intensive care units.

High level resistance to these fluoroquinolones in this setting might be because of the high level of empiric use of antibiotics as a result of inadequate laboratory facilities, incomplete and wrong usage of antibiotics, high level of abuse as a result of over the counter acquisition of antibiotics and the possibility of having substandard drugs in the market [21]. More studies should be carried out to determine the relationship between level of consumption of these fluoroquinolones and the level of resistance.
Susceptibility of E. coli to norfloxacin was quite low, $2.2 \%$ with the highest susceptibility of norfloxacin being $9.1 \%$ in 2006 . This is contrary to the result obtained from a similar study carried out in rural Tamilinadu where susceptibility to norfloxacin was $94.44 \%$ [18]. According to reports published in 2000, quinolone susceptibility was greater than $95 \%[12,19]$. Generally, the susceptibility levels got in this study is lower than that got from previous studies carried out in developed countries [20]. This could possibly be because of the ease of access to antibiotics over the

There is need for constant antimicrobial surveillance to detect emerging antibiotic resistance patterns. This is also important in the development of hospital antibiograms in order to facilitate the use of the right antibiotics for the treatment of bacterial infections at the local level. Also in Nigeria, where over the counter acquisition of antibiotics have been implicated as one of the reasons for the development of resistance [6], policies should be put in place to control this. This will help curb the scourge of bacterial resistance.

The introduction of electronic laboratory databases which can be analysed with the help of simple software packages such as the WHONET software which can be obtained free from World Health Organisation [22], will greatly help in antibiotic surveillance.

\section{Conclusion}

This study has shown that E.coli is a predominant bacterial pathogen in community acquired bacterial infections. There is also a high level of resistance of E.coli to fluoroquinolones in the community. Inasmuch as there is reasonable level of resistance to fluoroquinolones, they will still be useful in the management of urinary tract infections, because they are excreted in the urine unchanged, hence enhancing their effects and E.coli has been indicated as the most common pathogen in urinary tract infections. However, for other sites, it is recommended that fluoroquinolones should not be used for empiric treatment. Proper laboratory tests should be carried out to determine pathogenic organism and sensitivity profile. Furthermore, there is need to set up proper antimicrobial surveillance systems in health institutions through which hospital antibiograms will be developed. Antibiotic cycling should also be implemented to help slow the rate of resistance development. Further studies should be carried out in the region to evaluate the effect of antibiotic utilization on bacterial resistance.

\section{COMPETING INTERESTS: None}

AUTHORS' CONTRIBUTIONS: COE and NCO designed the study protocol, NCO and OIE carried out the analysis and interpretation of data. NCO drafted the manuscript. All authors read and 
approved the final manuscript. NCO and OIE are the guarantors of the paper.

\section{REFERENCES}

[1] P.G. Ntagiopoulos, E. Paramythiotour, A. Antoniadour ,H. Giamarellou, A. Karabinis. "Impact of an antibiotic restriction policy on the antibiotic resistance patterns of Gramnegative microorganisms in an Intensive Care Unit in Greece", Int J Antimicrob Agents , Vol 30, 2007,pp. $360-365$

[2] P. Hsueh, P.E. Badal, S.P Hawser, D.J Hoban, S.K Bouchillon, Y. Ni et al, ‘Epidemiology and antimicrobial susceptibility profiles of aerobic and facultative Gram-negative bacilli isolated from patients with intra-abdominal infections in the Asia-Pacific region: 2008 results from SMART (Study for Monitoring Antimicrobial Resistance Trends)', Int J Antimicrob Agents , Vol 36, 2010, pp. 408 414.

[3] J.L. Crandon, J.L Kuti, R.N. Jones, D.P. Nicolau, 'Comparison of 2002-2006 OPTAMA progress for US hospitals: focus on Gram-negative resistance', Ann Pharmacother, Vol 43, 2009, pp. 220 - 227

[4] W.C Ko, P.R Hsueh, 'Increasing extended spectrum $\beta$-lactamase production and quinolone resistance among Gram-negative bacilli causing intra-abdominal infections in the Asia-Pacific region: data from SMART study 2002 - 2006', J Infect, Vol 59, 2009, pp. $95-103$

[5] S. Njissen, A. Florijn, M.J. Binten, F.J. Schmitz, J. Verhoef, A.C. Flut, 'B-lactam susceptibilities and prevalence of ESBL producing isolates among more than 5000 European Enterobacteriaceae isolates', Int J Antimicrob Agents, Vol 24, 2004, pp. 585 591

[6] I.N. Okeke, K.P. Klugman, Z.A. Bhutta, G.D. Adriano, P. Jenkins, T. O'Brien et al. "Antimicrobial resistance in developing countries 2: Strategies for containment" Lancet Infect Dis , Vol 5, 2005, pp. 568 - 80

[7] T.M. Hooton, R. Besser, B. Foxman, T.R Fritsche, L.E. Nicolle, "Acute uncomplicated cystitis in an era of increasing antibiotic resistance: A proposed approach to empirical therapy", Clin Infect Dis, Vol 39 No.1, 2004, pp. 75 - 80

[8] K. Gupta, T.M. Hooton, C.L. Wobbe, W.E. Stamm, "The prevalence of antimicrobial
ACKNOWLEDGEMENT: The authors wish to appreciate Mr Larry who assisted in data collection. resistance among uropathogens causing acute uncomplicated cystitis in young women", Int J Antimicrob Agents, Vol 11, 1999, pp. $305-308$.

[9] J.A. Karlowsky, M.E. Jones, C. Thornsberry, I. Critchley, I.J. Kelly, D.F. Sahm, "Prevalence of antimicrobial resistance among urinary tract pathogens isolated from female outpatients across the US in 1999", Int J Antimicrob Agents, Vol 18, 2001, pp. $121-127$

[10] J.A.Karlowsky, C. Thornsberry, M.E. Jones, D.F. Sahm, "Susceptibility of antimicrobial resistant urinary Escherichia coli isolates to fluoroquinolones and nitrofurantoin", Clin Infect Dis, Vol 36, 2003, pp. 183 - 187

[11] J.A. Karlowsky, I.J Kelly, C. Thornsberry, M.E. Jones, D.F. Sahm, "Trends in antimicrobial resistance among urinary tract infection isolates of Escherichia coli from female outpatients in the United States", Antimicrob Agents Chemother, Vol 46, 2002, pp. $2540-2545$

[12] J.A. Karlowsky, I.J. Kelly, C. Thornsberry, M.E. Jones, A.T. Evangelista, I.A. Critchley et al, "Susceptibility to fluoroquinolones among commonly isolated Gram-negative bacilli in 2000: TRUST and TSN data for the United States" Int J Antimicrob Agents, Vol 19, 2002, pp. $21-31$

[13] Y. Karaca, N. Coplu, A. Gozalan, O. Oncul, E. Citil, B. Esen. "Co-trimoxazole and quinolone resistance in Escherichia coli isolated from urinary tract infections over the last 10 years" Int J of Antimicrob Agents, Vol 26, 2005, pp 75 - 77.

[14] Clinical and Laboratory Standards Institute. Performance standards for antimicrobial susceptibility tests, 21 st informational supplement, Vol 31 No.1,2011.

[15] N. Kashef, G.E. Djavid, S. Shalbazi, "Antimicrobial susceptibility patterns of community acquired uropathogens in Tehran, Iran", J Infect Dev Countries, Vol 4 No.4, 2010, pp. 202 - 206.

[16] S. Thibaut, J. Caillon, C. Huart, G. Grandjean, P. Lombrall, G. Potel G et al, "Susceptibility to the main antibiotics of Escherichia coli and Staphylococcus aureus 
strains identified in community acquired infections in France. (MedQual 2004 2007)", Medicine et Maladies Infectieuses, Vol 40, 2010, pp. $74-80$

[17] K.T. Wariso, I.M. Siminialayi, J.O. Odigie, "Pattern and antibiogram of urinary tract infection at the University of Port Harcourt Teaching Hospital", Asian Pacific Journal of Tropical Medicine 2010, 1-5

[18] A. Manpand, A.A. Al-Salamah, M. Amuthan, " Prevalence and antibiotic susceptibility of uropathogens in patients from a rural environment, Tamilnadu", Am J Infect Dis Vol 6(2), 2010, pp. 29 - 33
[19] M. Chomarat, " Resistance of bacteria in urinary tract infections", Int J Antimicrob Agents,, Vol 16, 2000, pp. $483-7$

[20] G.C. Schito , "Why fosfomycin trometamol as first line therapy for uncomplicated urinary tract infections", Int J of Antimicrob Agents, Vol 22(2), 2003, pp. $79-83$

[21] A. Raufu, " Influx of fake drugs to Nigeria worries health experts”, BMJ, Vol 324, 2000, pp.698.

[22] D.L. Monnet, "Toward multinational antimicrobial resistance surveillance systems in Europe", Int J Antimicrob Agents, Vol 15, 2000 pp. 91 - 101 